\title{
Upper Lobe of the Left Lung
}

National Cancer Institute

\section{Source}

National Cancer Institute. Upper Lobe of the Left Lung. NCI Thesaurus. Code C33021.

The smaller lobe of the left lung, situated above and in front the oblique fissure, which includes the apex. 